\title{
Identifying merit and potential beyond grades: Opportunities and challenges in using contextual data in undergraduate admissions at nine highly selective English universities
}

\author{
Anna Mountford-Zimdars and Joanne Moore, both Graduate School of Education, University of Exeter \\ Contact: a.mountford-zimdars@exeter.ac.uk
}

To Cite: Mountford-Zimdars, A and Moore, J (2020) Identifying merit and potential beyond grades: Opportunities and challenges in using contextual data in undergraduate admissions at nine highly selective English universities, Oxford Review of Education.

\section{Acknowledgments:}

The authors would like to acknowledge the support of the Fair Education Alliance in funding the research and the involvement of staff members at the nine case study institutions who kindly contributed to the research. Louise Higham undertook additional research with sector stakeholders as part of the wider review of contextual admissions not reported in the present article.

\section{Declaration of interest statement:}

There are no potential conflicts of interest.

\begin{abstract}
:
Highly selective higher education institutions (HEls) are simultaneously mandated to enable access for populations which have traditionally been excluded ('equality'), and to ensure that admitted students have the potential to succeed in higher education ('excellence'). This article uses original empirical casestudy data from 2018, from nine highly selective English HEls, to explore current uses of contextual data in undergraduate admissions. The results show that all participating HEls thought holistically about their applicants. In particular, HEls considered the context in which applicants had achieved their grades, and aimed to identify academic potential not captured by those grades. However, ideological and theoretical disagreements, as well as practical barriers, hamper a more widespread and consistent application of contextual data in English undergraduate admissions. The article therefore identifies further practical steps for HEls and other stakeholders that would enable a more valid, evidence-based and coherent position on contextual data use across the HE sector. Overall, advancing more consistency in how contextual data were used might enable greater certainty among applicants, and those advising them, regarding how applications for admissions are likely to be judged. Ultimately, contextual admission policies have the potential to increase diversity among the admitted students at selective HEls.
\end{abstract}

Keywords: contextual admission; social class, social mobility, inequality, widening participation, access 


\section{Introduction}

Opportunities for entry into higher education (HE) are not equally distributed among social groups. In countries with tiers of particularly selective 'elite' universities, inequality is 'effectively maintained' (Lucas, 2001 ) in that access inequalities are greatest among the most selective tiers. Thus, admissions criteria and processes are particularly fiercely contested there (Zimdars 2016). In the United States, there are increasing moves to abandon the reliance on standardised admissions tests like the SAT and ACT, and to focus instead on school leaving grades; a notable recent proposal in this regard came from the University of California system (Hartocollis, 2019a). The commercial testing companies are fighting back with promises of more nuanced measures of disadvantage that would enable universities to understand admissions scores in a wider context; this move, though, seems to have come to a halt in the wake of protests (Hartocollis, 2019b). Affirmative action, quota and percentage schemes, and special treatment for athletes and alumni children continue to engender controversy and litigation (Pennington, 2019). Threats by President Macron of France - to increase equity in higher education access, through abolishing the leading feeder university for French civil servants, the École Nationale d'Administration (Matthews, 2019) - led eight grandes écoles to submit to the French government, in October 2019, their proposal to widen access. In South Africa, black students excluded during the years of apartheid from the advantages of accessing and succeeding in selective higher education (Mzangwa, 2019) have not yet seen equal access delivered by the 2002 National Plan on Education.

In the UK, the profile of the student population, particularly within more elite HEls is more likely to have been educated in fee-paying schools, with the most selective or 'elite' institutions: those who require the highest prior school grades for admission. When considering multiple equality factors simultaneously, for example UCAS' Multiple Equality Measures (MEM) (UCAS 2019, p.8), children attending nonselective state schools, who were in receipt of free school meals, and who lived in areas of high economic disadvantage, were 9.8 times less likely to progress to higher-tariff providers than the most advantaged (UCAS, 2017).

For England, differences in progression to higher education are partly - but not completely - explained by the lower general levels of attainment associated with disadvantaged students. Even among highachieving students who do attend university, the relatively small group of students from lower socioeconomic backgrounds who achieve high grades are less likely to attend a high-tariff university than their more privileged peers (Chowdry, Crawford, Dearden, Goodman, \& Vignoles, 2013; Crawford, 2014). In theoretical terms, this continued difference has been conceptualised as 'effectively maintained inequality' (Lucas, 2001); while educational expansion and increases to the length of compulsory schooling allow a decrease in socio-economic differences in the length of education to which young adults have access (Raftery \& Hout, 1993), there are continued differences in the quality of education accessed by different socio-economic groups, and this is particularly evident at the secondary and tertiary levels (e.g., Crawford, 2014).

The UK is perhaps unusual in an international context in terms of the extent to which policymakers see universities themselves as the moderators of inequality, and change agents in relation to unequal patterns of participation in access, success and progress, within both higher education and the workplace. The English regulator for higher education, the Office for Students (OfS) has set a target to eliminate 'the gap in entry rates at higher-tariff providers between the most and least represented groups' (OfS, 2020). In order to sustain their licence to operate, higher-education providers (HEP) are required to have an 'Access and Participation Plan' in place that explains how the HEP is increasing equity in access, success and progress. In return, significant funding is available for widening 
participation (WP), with higher education institutions' spend on WP in 2016-17 totalling £745.6 million (OfS, 2019).

This article explores and evaluates contextual admissions as a tool used increasingly by UK universities in order to achieve their targets of reducing the differences between various social groups in terms of their access to HE.

Contextual data in admissions has featured in a number of UK policy documents by governmental bodies making recommendations for policy and practice (Milburn, 2012; All Party Parliamentary Group on Social Mobility, 2017). At its core, contextualisation simply means that universities are asking for and using data and information that will help them understand the context of the applicant (MountfordZimdars et al. 2016).

In the US, such contextualisation is practised by Ivy League institutions and others using 'holistic admissions' (Stevens, 2007). Contextualisation is used to understand the personal and social as well as the educational context of applicants. On the one hand, this allows for individualised holistic case-bycase consideration. A field-experiment with admissions staff at eight selective US institutions demonstrated that holistic considerations of applicants' context can improve admissions success for disadvantaged applicants in high-stakes admissions (Bastedo et al. forthcoming). Perhaps surprisingly, however, for a system that has a reputation for privileging individualistic notions of success, in reality the process is also about 'crafting a class' (Stevens, 2007). Together, the student body should display certain characteristics in terms of their ethnic, sporting, and other attributes, with alumni ties being perhaps the most controversial factor considered in holistic admissions (Kahlenberg, 2010). Arguably, a less controversial aim of this policy is the creation of diverse learning environments to prepare students for life and leadership in a diverse society (Zimdars, 2016).

In the UK, contextualisation has almost exclusively been used for understanding educational contexts, and there is less focus on personal or other factors. Contextualisation describes 'data matched to applicants (including through outreach) in order to assess an applicant's prior attainment and potential to succeed in higher education in the context of the circumstances in which their attainment has been obtained' (Mountford-Zimdars, 2017). While some universities allow applicants to complete an 'extenuating circumstances' form that can highlight events that affected attainment, the system is not intended to contextualise each applicant on a case-by-case basis. The bottom line is always: does this contextualisation mean that the applicant has more potential to succeed in higher education than indicated by their prior attainment? A discourse of crafting diverse classes is absent (anonymised, 2016).

There is now a body of evidence for the practice of making contextual or lower offers; this comes from multi-institutional studies (Sutton Trust, 2017), national-level analyses (HEFCE, 2005, 2014; Crawford, 2014), and research from the Universities of Cardiff, Bristol, and Oxford. This has shown that those admitted with lower grades in school (A-levels for most studies; GCSEs for the Oxford research) and identified as disadvantaged achieved as well as, and better than, their more privileged peers (Ogg, Zimdars \& Heath, 2009; Hoare \& Johnson, 2011; Taylor, Rees, Sloan, \& Davies, 2013; Jones, Pampaka, Swain, \& Skyrme, 2017). However, overall, the evidence on what constitutes raw potential in HE is still relatively weak, and requires re-evaluation in the light of continuous changes in young people's qualifications.

Previous research on contextual admissions identified how particularly the privileging of academic selectivity in admissions constrains progressive admissions policies in globally competitive universities (Boliver, Crawford, Powell, \& Craige, 2017). The present article explores further the fundamental questions raised, for decision-makers, by the use of contextual data. These are questions about what constitutes and indicates 'merit and potential' in undergraduate admissions. Also, there are differing normative views on how one should best use information on contextual factors, as well as applied consideration as to what works in the use of contextual data. 
Thus, we aimed to uncover in detail perceptions of and practices around the use of contextual data in highly-selective institutions, and to provide insights and examples to support the future development of scholarly theoretical and applied work in this area. We focused on high-tariff HEls in England, where competition for places, and high entry standards, imply these institutions are more likely to be prohibitive for educationally disadvantaged students lacking a background of exposure to higher education (Shiner \& Noden, 2014; Archer, DeWitt, \& Wong, 2014). These students are less likely on average to reach the standard required attainment for admissions; they may be deterred by an institution's reputation for exclusivity; they may lack the social and cultural capital to compete with more advantaged applicants with greater access to different life experiences, academic coaching, and better HE-related careers advice (Anders, 2017; Archer et al., 2014); and they have low expectations of whether a higher education outcome is likely (Harrison \& Waller, 2018).

\section{Method}

We employed a qualitative case study methodology because of its utility in exploring complex social phenomena, recognising the limitations of research in that the findings are context-specific. Starting with their entry profile and geographic location, we identified and successfully invited nine English HEPs to take part in the study. All institutions had pre-1992 foundations and were oversubscribed; they also had a research focus, and the highest possible school-leaving grades as admissions requirements. We achieved maximum geographic spread of the locations of the institutions, including large urban and small-town institutions.

While all providers had adopted contextualised admissions practices, their actual enrolment statistics made them more exclusive than the general sector. Full-time undergraduate entrants from state schools and colleges across the cases ranged from 57.7 to $88.4 \%$, compared to a $90.0 \%$ sector average. The share of entrants from Low Participation Neighbourhoods (LPN) ranged from 3.0 to $9.6 \%(11.4 \%$ sector average; HESA calculates a location adjusted benchmark to take into account some of the factors which contribute to the differences between providers since due to location and other variability the average values are not necessarily helpful when comparing providers). The institutions were considered illustrative of a type of organisational identity characterised by Boliver et al. $(2017$, p.151) as 'the globally competitive university'.

In-depth case studies were undertaken in spring 2018. This involved reviewing written admissions, contextual data policies, and descriptions of practices, followed by interviews $(n=22)$ with admissions staff, data managers, and WP practitioners involved in designing and implementing the contextual admissions policies. Informal semi-structured interviews were used instead of questionnaires, on the basis that they would produce more genuine information and avoid the problem of the researcher's preconception of the phenomenon affecting the research results. Two researchers conducted the interviews. They typically lasted between 40 and 70 minutes each; this yielded over 20 hours of recordings in total. Selective transcription and field notes by the researchers then formed the basis of their thematic analysis. University ethics approval was granted, covering GPDR compliant data collection, information, consent and withdrawal processes and storage on password protected networks (link to university research GPDR guidance, anonymised 2019). Using MaxQDA we coded scripts at a content and conceptual level. The present academic paper focuses on the conceptual codes with some process aspects feeding into more detailed policy dissemination.

Table 1 provides an overview of the characteristics of the nine HEPs. The organisation of undergraduate admissions functions varies across institutions, and the interview sample reflected this. As a minimum, the research included an interview with the director and/or head of undergraduate admissions with responsibility for contextualised admissions $(n=12)$. Where appropriate to the institutional context, interviews were also undertaken with staff responsible for WP/outreach provision $(n=5)$ and admissions data/processing or research functions $(n=5)$. The approach was iterative, through stages of desk 
research and qualitative interviews, to ensure accuracy, clarity and completeness of the information obtained, and adequacy of interpretation and aggregation of any contradictory interpretations.

Table 1: Overview of cases

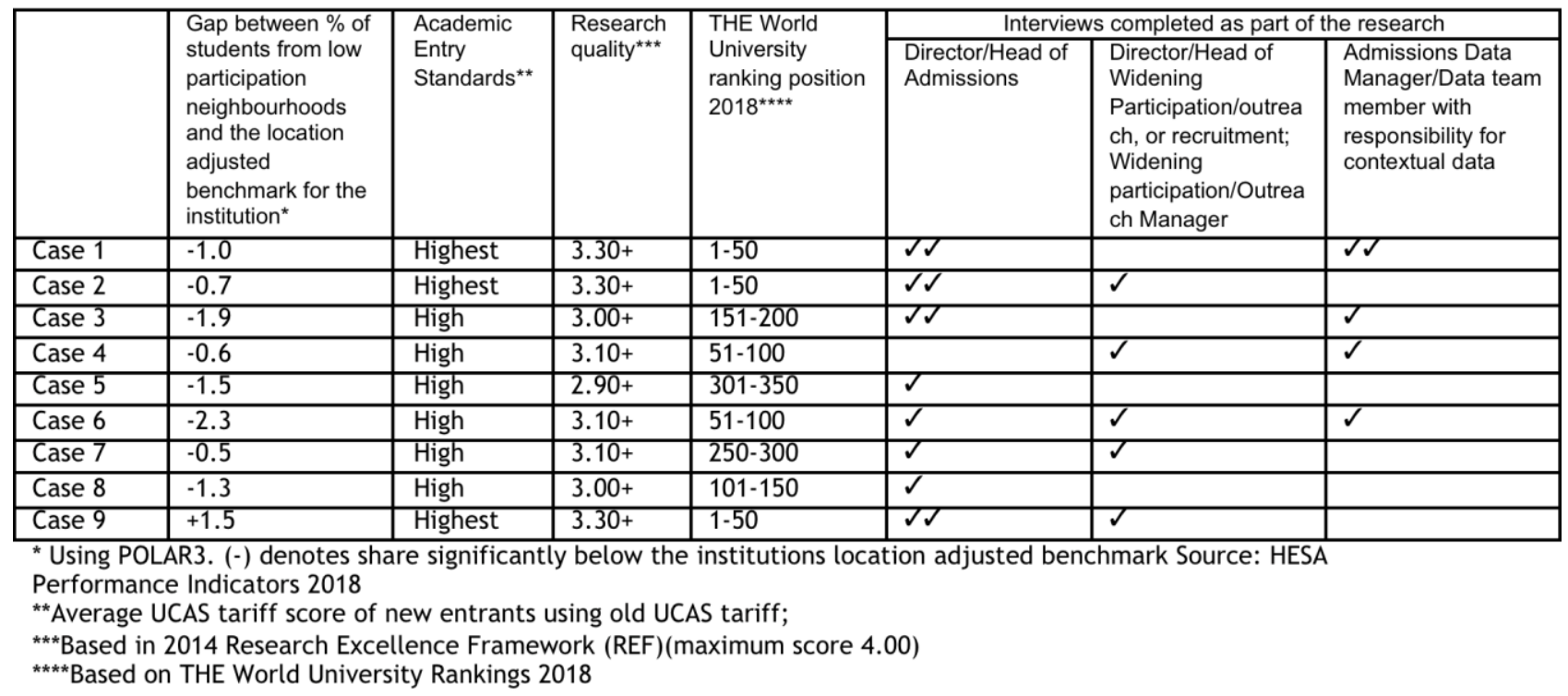

Across the nine institutions, the data analysis compared how institutional contextual factors, and the implicit and explicit approaches to defining and identifying merit and potential in admissions, affected the practice of contextualised admissions. The documentary and interview data were analysed to identify the common and distinctive themes emerging, which were then mapped against a series of institutional factors, including the loci for admissions decisionmaking (centralised/devolved), and the nature of the processes for assessing merit (application of academic criteria, non-academic criteria, additional tests, interviews and so on).

A limitation of the research is that it does not cover all highly selective institutions in the UK. We restricted the sample to English institutions, as different fee and funding regimes can be in place in Scotland, Wales, and Northern Ireland. Also, we focused on high-tariff institutions. Generally, students who miss out on a place at one of these will be admitted to lower-tariff institutions, and are not completely missing out on an HE experience. We do not focus on contextualisation at low- or no-tariff institutions. Contextualisation at those institutions might identify those who could benefit from higher education, but are missing out on any HE opportunities due to leaving school early or low attainment. This would be a worthwhile investigation, and is one that we propose for future research.

\section{Findings}

\section{Motivation for contextualisation}

All interviewees agreed with an overall notion of improving 'fairness' in admissions. However, they differed in how they described the primary motivation or purpose of using contextualised admissions. For some this was about fairness as social justice i.e. redistribution of opportunities across social groups; for others, it was about allowing for empathy for individual background circumstances; and for a third group, contextual data use was about professionalism in admission practices, because it meant taking account of information relevant to decision-making. One respondent presented an institution that selected among 20,000 high-achieving applicants for 1,500 places, and that had succeeded in exceeding the target given to it by the regulator for recruitment of students from low-participation neighbourhoods. They described 
how there has been a longstanding commitment to holistic admissions, coupled with processes and systems that aim to minimise bias, plus the use of dedicated admissions staff with time and specialist expertise to undertake detailed scrutiny of applications to inform selection decisions.

...the driver for contextual data came from very high up in the organisation, someone started 15 years ago to recruit more widening participation students... her life experiences made her believe in WP and the current and previous directors are all very keen on widening participation. (Case 9)

Clearly, interviewees working in admissions teams were also cognisant of the policy imperative to widen their student profiles from the sector regulator OfS; and they were keen to utilise contextualised admissions to meet student diversity objectives. One interviewee in an institution that had made a commitment to contextualised admissions within the last five years spoke about the importance of linking government policy and institutional targets, together with benchmarking to achieve buy-in for contextual data policies in admissions.

\begin{abstract}
Expressing the objectives [of contextual admissions] within the institution's Access Agreement commitment helped to ensure that the work was prioritised, which was important since decisionmakers were facing competing priorities - to increase the 'quality' of the student intake which might run against student diversity objectives. ... using contextual data as part of admissions decision-making enabled a pro-active approach to giving additional consideration to students with potential to succeed, whilst balancing out competing institutional priorities. Selectors have to specify their reasons in each case for not taking forward an application from contextually flagged candidates who meet the entry standard. They also have the opportunity of making 'concessionary offers' to applicants who demonstrate potential to succeed. (Case 5)
\end{abstract}

While all providers acknowledged the wider policy context, respondents described how key arguments were won by making the internal case for the use of contextualisation in order to enhance the academic excellence of the institution. Arguments thus stressed the importance of contextual data for identifying potential, rather than for eliminating broader inequalities in society, or in the hierarchical English higher education system: the focus was squarely on using contextual data on a case-by-case basis to help to identify individuals with potential who might otherwise be overlooked. The first rows in Table 2 summarise the ideological perspectives respondents voiced in support of and against contextualised admissions.

While contextual data use was firmly embedded into the admissions processes at the case study institutions, contextualisation also attracted criticism. Perhaps surprisingly, objections did not reflect a fear of challenge in the media or from their 'traditional' constituency of students, but concerns about admitting students unprepared for the rigours of studying at an exclusive institution.

\title{
Availability and use of data
}

Our respondents also discussed: technical and pragmatic considerations regarding the operationalisation of contextualisation; the extent to which the available data support contextualisation; and how admissions practitioners are dealing with the perceived admissions risks. The Schwartz report set expectations for contextual data: the factors considered need to be relevant and accurate, and to allow all applicants equal opportunity to demonstrate their potential (Higher Education Steering Group, 2004). The use of contextual data arguably offers some advantages for greater transparency of the basis of admissions decisions, although there are also associated practical and data quality issues which need to be considered (Table 2). The main criticisms of the use of data/metrics to contextualise applicants relate to issues concerning the reliability and accuracy of the proxy measures of disadvantage that can currently be applied (Gorard, Boliver, Siddiqui, Banerjee, \& Morris, 2017). The second part of Table 2 shows the practical arguments, for and against contextual data, made by the respondents in the present project. 
Table 2: Ideological and practical perspectives in support of and against contextualisation

\begin{tabular}{|c|c|}
\hline \multicolumn{2}{|c|}{ Ideological perspectives for and against contextualisation } \\
\hline For & Against \\
\hline $\begin{array}{l}\text { Social Reproduction: unless addressed, wider } \\
\text { social inequalities are reproduced within } \mathrm{HE}\end{array}$ & $\begin{array}{l}\text { Social engineering: } \\
\text { application prejudices other groups of } \\
\text { applicants }\end{array}$ \\
\hline $\begin{array}{l}\text { Social justice: interventions in education are an } \\
\text { important mediator of social mobility }\end{array}$ & $\begin{array}{l}\text { Academic freedoms: Not role of HEls to } \\
\text { address inequalities in society }\end{array}$ \\
\hline $\begin{array}{l}\text { Potential-based: qualifications of educationally } \\
\text { disadvantaged students under-state their } \\
\text { academic potential to succeed at university }\end{array}$ & $\begin{array}{l}\text { Prior credentials: prior qualifications are the } \\
\text { best predictor of success at university. }\end{array}$ \\
\hline $\begin{array}{l}\text { Diversity: diverse enrolment profiles benefit the } \\
\text { academy and raise academic standards }\end{array}$ & $\begin{array}{l}\text { Elitist: contextual admissions 'sets students } \\
\text { up to fail' }\end{array}$ \\
\hline $\begin{array}{l}\text { Professional practice: broaden pool of potential } \\
\text { students to the institution }\end{array}$ & $\begin{array}{l}\text { Individualistic: subjective interpretation of } \\
\text { the meaning of the data could lead to } \\
\text { unconscious bias }\end{array}$ \\
\hline \multicolumn{2}{|c|}{ Practical perspectives for and against contextualisation } \\
\hline For & Against \\
\hline $\begin{array}{l}\text { Allows discerning potential in a competitive } \\
\text { applicant pool }\end{array}$ & $\begin{array}{l}\text { Need to maintain holistic assessment in light } \\
\text { of data }\end{array}$ \\
\hline $\begin{array}{l}\text { Possible to share contextualisation criteria with } \\
\text { applicants }\end{array}$ & $\begin{array}{l}\text { Judgements based on the basis of } \\
\text { contextual data are still subjective and in the } \\
\text { light of data quality issues could be } \\
\text { unreliable and may not improve the system }\end{array}$ \\
\hline $\begin{array}{l}\text { Data potential: the development of 'fit for } \\
\text { purpose' datasets relating to HE applications is } \\
\text { not an insurmountable challenge }\end{array}$ & $\begin{array}{l}\text { Data risks: data quality flaws can lead to } \\
\text { questionable admissions choices and } \\
\text { introduce another type of unfairness }\end{array}$ \\
\hline $\begin{array}{l}\text { Metrics as part of predictive analytics builds the } \\
\text { evidence to show the relationship between past } \\
\text { achievement and future potential }\end{array}$ & $\begin{array}{l}\text { Comparing performance based on context } \\
\text { implies a deficit model }\end{array}$ \\
\hline $\begin{array}{l}\text { Datasets can highlight the groups that have been } \\
\text { shown to have good potential for success in HE. }\end{array}$ & $\begin{array}{l}\text { The analyses of patterns is based on past } \\
\text { conditions which might be hard to replicate. }\end{array}$ \\
\hline $\begin{array}{l}\text { Internal WP monitoring: application of data in } \\
\text { decision making can support a diverse student } \\
\text { body }\end{array}$ & $\begin{array}{l}\text { Concerns about external perceptions: hard- } \\
\text { working applicants merit consideration in } \\
\text { their own right }\end{array}$ \\
\hline $\begin{array}{l}\text { Data can be applied systematically and save } \\
\text { resources across the student life-cycle }\end{array}$ & $\begin{array}{l}\text { Pragmatic perspective: resource implications } \\
\text { in using contextual data }\end{array}$ \\
\hline
\end{tabular}

There are currently gaps in the data accessible to institutions for admissions purposes, and potentially useful individual-level data, such as data on family income or eligibility for free school meals, are not made available at the point of application. Therefore, there is a focus on proxies for disadvantage, linked to postcode or school/college education provider. Table 3 identifies the range of data currently employed as contextual flags across our nine case studies. Even where institutions were using the same data source, the definitions used for contextual data flagging differed. For example, although all utilised POLAR (Participation Of Local AReas) data, a national classification that groups areas across the UK 
based on the proportion of the young population that participates in higher education, the thresholds used to identify applicants from areas with a poor tradition of higher education varied.

Table 3: Types of data in use by the nine case study institutions:

\begin{tabular}{l} 
Level/Type \\
Education (schooling) level: \\
Measure of low general attainment \\
Measure of low historical higher education progression \\
\hline Geo-demographic (area) level: \\
Measure of low higher education progression (POLAR) \\
Measure for low socio-economic group (ACORN) \\
Measure for relative disadvantage (Output area classification (OAC) and Index \\
of Multiple Deprivation (IMD)) \\
\hline Individual level: \\
Time in care measure \\
Disability \\
Widening participation scheme participant measure \\
Extenuating circumstances form \\
Mature applicant
\end{tabular}

Decisions of this type are underpinned by pragmatic considerations in terms of the share of applicants being flagged. In general, admissions teams were aiming for a flagging process that was capable of identifying sufficient numbers of candidates to be meaningful, but not such high proportions as to skew the profile and make the process unmanageable (10-20\% of applicants). Changes in the data being applied over time illustrate the desire in the institutions to improve the quality of the data as new insights or information become available. Because different institutions have different starting points in terms of their application profile and the aims of contextualisation, this complicates any endeavours to agree data used across the whole sector. At the same time, participants in this research were keen for more consistency in the data being applied for contextualisation, with a view to promoting greater transparency to potential applicants: one of the case study institutions advocated a self-assessment tool for applicants that would enable them to work out, using an online social background tool, the grade reduction for which they would be eligible.

We found two diverging trends among our case study institutions regarding data use. On the one hand, some institutions were seeking to use increasingly nuanced data, at as fine a level of granularity as possible, in order to increase assurance of reaching target groups. On the other hand, other providers used more 'sector standard' indicators linked to national monitoring of institutions.

Examples of using data at a finer level of granularity included drawing on small-area statistics, or triangulating using multiple data sources. An interviewee at an elite institution with highly devolved admissions decision-making said:

just because I live in a postcode where people read the Sun and work in industry doesn't mean that I do... We quite often use multiple indicators to test if [the applicants] are disadvantaged or under-prepared... when we use a variety of indicators and several light up as opposed to none, we get a more genuine sense of where they came from. (Case 1)

In institutions that use multiple sources independently, selectors are presented with a wide range of indicators as part of holistic decision-making. In these cases, weaknesses in data are less noteworthy, since the process is working towards drawing out the relative individual merits of applicants, which can then be assessed through other means (e.g. interviews or selection days). The function of the data is to prompt selectors to consider applicants who might otherwise be overlooked. Furthermore, there has been a desire to identify candidates who can be shown to be exceptional 'shining stars' in some sense by performing above the norm relative to their peer group.

... we're lucky because we have a gathered pool... so we're looking at everyone at once... School performance is important... Every applicant is given a contextualised GCSE score 
looking at how their performance compares to attainment at other similar schools... it shows whether they are highly performing from a low-performing school... Guidance in the framework says - unless there is a reason not to - applicants with a WP flag should be invited to interview; that way they will get a chance to shine. (Case 2)

The second, divergent trend was moving more in the direction of using 'sector standard' indicators of WP. This had the advantage of linking not only to institutional targets in national monitoring, such as the Access and Participation plans, but also to Teaching Excellence Framework (TEF) benchmarking categories. A further advantage was that this allowed the use of data that were relatively straightforward to obtain. For example, one interviewee in an institution using POLAR (quintile 1) data to contextualise applicants said that

... within the regular and end-of-cycle reporting on the number of applications and offers made, replies and acceptances are making the outcomes from the contextual data strategy more visible to senior management. Getting buy-in is considered an important achievement as there was some trepidation across schools and departments; having a target and being able to show improvement year on year has helped to stem potential objections to the contextual data approach. (Case 5)

While POLAR featured in all cases (Table 3), most did not use this independently of other measures. POLAR is flawed, not only because of the ecological fallacy argument previously raised in the quote from Case 1, and generally-known issues around the validity of POLAR in densely populated areas like London, but also because it uses historical patterns of progression. Providers' ability to use contextual data is challenged by a constantly shifting data landscape. For example, analysis at one case has suggested that shifting from a definition of disadvantage based on POLAR3 to one based on POLAR4 would result in a significant shift in terms of which applicants are flagged in the contextual admissions process, with consequent effects for admissions objectives and comparison of data year-on-year. The TEF metrics already split 'success for all' by the Index of Multiple Disadvantage (IMD) as well as by POLAR, suggesting that a greater use of IMD in future benchmarking and targets is likely.

Overall, the research participants all highlighted that using contextual data in admissions requires a high level of forward planning and extensive resource commitment. There was no single approach to how and where contextual data should sit within institutional operations and governance structures. Examples were found of decisions being made through line management arrangements, through existing admissions governance structures, and through the establishment of cross-institutional working groups to oversee or advise on the strategic aspects of contextual data use.

The main challenge is the amount of resource needed to deliver, because of the way information provided to us... [needs] a lot of data cleaning and analysis before we're confident we can use it in our processes. For example, each year we have to source and match the school performance data and we've decided to use year-on-year averages to make information more stable because school performance rises and falls year on year. We do all that internally, and it's a huge job to source and prepare data into the system. We have been lobbying for improvements in the amount and type of data provided to us because it's a huge resource and time commitment, which could be provided and shared... We can deliver it because we've got a data team able to perform what's needed; smaller WP teams are less able to support... the enormity of pulling it together is prohibitive. (Case 4)

\section{Implications for admissions decisions}

While all interviewees were working towards ensuring that any applicant with potential to succeed in a highly selective institution has an equal chance of accessing their chosen place, different HE providers use contextual data differently within the application cycle. This diversity in approaches mirrors differences across the sector, in the types of data as well as how it is used (Crawford et al., 2017; Boliver et al., 2017; anonymised, 2013). There can also be differences within institutions, by programme area 
and by faculty, since the degree of discretion allowed to admissions decision-makers varies from completely centralised to completely devolved systems, furthermore, some institutions operate mixed models. In many institutions the offer-making policy is set at the institutional level; however in others, individual departments and faculties decide offers, and such offers may or may not apply full contextualisation, and may also be driven by the priorities of programme leads.

We distinguished the case study institutions into whether they use (1) Contextual Offers, or (2) Additional Consideration. The first approach involves offering contextually flagged applicants a contextual, or differential, or concessionary offer. This is usually at least one and sometimes two grades below the standard offer criteria for admission; thus, if the standard entry requirement for a course is AAA, it might be dropped to ABB for a contextual offer. (The advice to the sector from Supporting Professionalism in Admissions (SPA) stated that differential offers are recommended as long as supported by appropriate empirical evidence, and not used mechanistically to the wholesale advantage of one group of candidates over another, but as part of a holistic assessment.) Some, but not all institutions publish their contextual offers. An interviewee in a case study institution that has a particularly large gap in terms of achieving their local adjusted benchmark for WP students noted that

... applicants may apply with qualifications that do not accurately reflect their abilities and potential, and may have access to fewer opportunities than other applicants. We would consider making a contextual offer to an applicant if they meet the criteria... and applicants from these underrepresented groups will normally be eligible for the published Contextual Offer for their course. (Case 6)

While there is some evidence that students from disadvantaged backgrounds attain good degree results with lower school grades than their more affluent peers (Sutton Trust, 2017; HEFCE, 2005, 2014; Crawford, 2014; Ogg et al., 2009; Hoare \& Johnson, 2011; Taylor et al., 2013; Jones et al., 2017), respondents noted that the evidence base on what constitutes potential in HE is still relatively weak, and at risk due to changes in young people's qualifications. However, interviewees with the largest admissions gaps to close had a sense of needing to lower their offers, and were consequently researching whether students succeed with such lower offers. One example of this was from an institution that has recently extended the policy on differential offers to contextually flagged applicants from one to two grades. This provides for the students in terms of developing evidence over time, while trying to be mindful of the need to manage the risk (to the students).

Some interviewees were concerned that contextual offers could disincentivise high performance in schools, or lead applicants to accept the contextual offer as their insurance rather than as a firm choice. Others voiced concerns about reputational damage, and a drop in league-table rankings, from making reduced offers. There was also a feeling that a sector-wide movement on differential offers would be the greatest collective gain for institutions and individual applicants, with limits imposed on the present model of institutions working out their own policy.

The second approach was taken by institutions that used contextual data during candidate assessment as a way of giving additional consideration to contextually flagged applicants, using standard academic entry thresholds. In this scenario contextual data mainly fall within scope of 'assessing relative potential' within normative decision-making processes.

... we've been using contextual data for a number of years with the aim of 'shining a light' on applicants who through background and educational experience may have had less access to less opportunities. Seeing applicants achievement in context provides a framework to encourage admissions selectors to give educationally disadvantage applicants a close look: the degree to which the data is applied, and when in the application process, will depend on the course requirements and recruitment profile... The data suggest that ranking contextually flagged and non-flagged applicants separately according to their scores results in slightly more widening participation applicants being invited to interview. (Case 4) 
The case studies suggest that progressing contextually flagged applicants via a standard application route might be favoured by institutions with devolved admissions decision-making, because it allows for contextual decisions at the level of academic programmes. Plus, institutions in the position of affording applicants a high level of individual scrutiny, including the use of in-depth assessment procedures (e.g. courses that use interviews and admissions tests), might favour using contextual data in order to assess the relative merits of applicants with differing life experiences and influences on their performance as an applicant. The downside of the additional consideration approach is that it is less progressive than using contextual data to influence the offers made to educationally disadvantaged students who are less likely to meet the grade requirements; the approach might therefore only influence the profile of admissions decisions at the margins in two senses of the word: The margins of those who are borderline admissions applicants and the margins rather than the mainstream of the admissions process.

One case, with centralised undergraduate admissions processing, took the approach of creating one and later two dedicated professional service roles called 'the progression team' to advocate for applicants from WP backgrounds. These are

applicants who present with contextual data factors [and who] receive additional specific attention from the progression team...[they] sign off decisions on contextually flagged applicants who are academically more borderline (or senior management in the most complex of cases) [and] ensure there is consistency in approach, and provide the resource to undertake further investigations if required (e.g. getting additional information from the applicant, contacting the school for additional reference or discussion of school predictions)... a very effective way of allowing contextual data to be embedded in the process of holistic assessment, and [this] led to people getting offers who would not otherwise get a place. (Case 7)

Table 4 provides an overview of the points, during a standard application process, at which contextual data could be a factor in admission decisions. The different approaches to how data influence decisions across the case study institutions demonstrate two opposing motivations - on the one hand, the benefits of having a high degree of flexibility as part of an in-depth holistic consideration of the person; on the other hand, the benefits of having a rules-based approach to the application of contextual data, which reflects the institutional objectives and assessment of applicant potential in relation to institutional targets. Overall, the research highlights that institutions use a variety of approaches to the task of contextualising applicants, which is in line with the autonomy of institutions and the different requirements and admissions needs between providers. This was expressed as follows by two respondents.

... our admission principles and practicalities are supportive of contextualised admissions principles on how to use it, but it's a challenge when people want to apply it mechanistically: they want to be able to say this a flag and therefore the applicant is WP; however it needs to be used alongside other information on the application form, and bearing in mind the disadvantages and advantages of different data... It helps to identify those more likely to be WP, but is not a 'be-all or end-all'... just part of the process... there is confusion who is a WP student... there's no single definition or proxy for low socio-economic class and low progression to HE... it's much more nuanced than that and admissions and WP reflect individual institution's priorities and characteristics. (Case 4)

... we need to get away from crude labelling of applicants... i.e. to make sure there is a human judgement element rather than simply data being applied. (Case 2) 
Table 4: Different types of contextualisation and implications for applicants

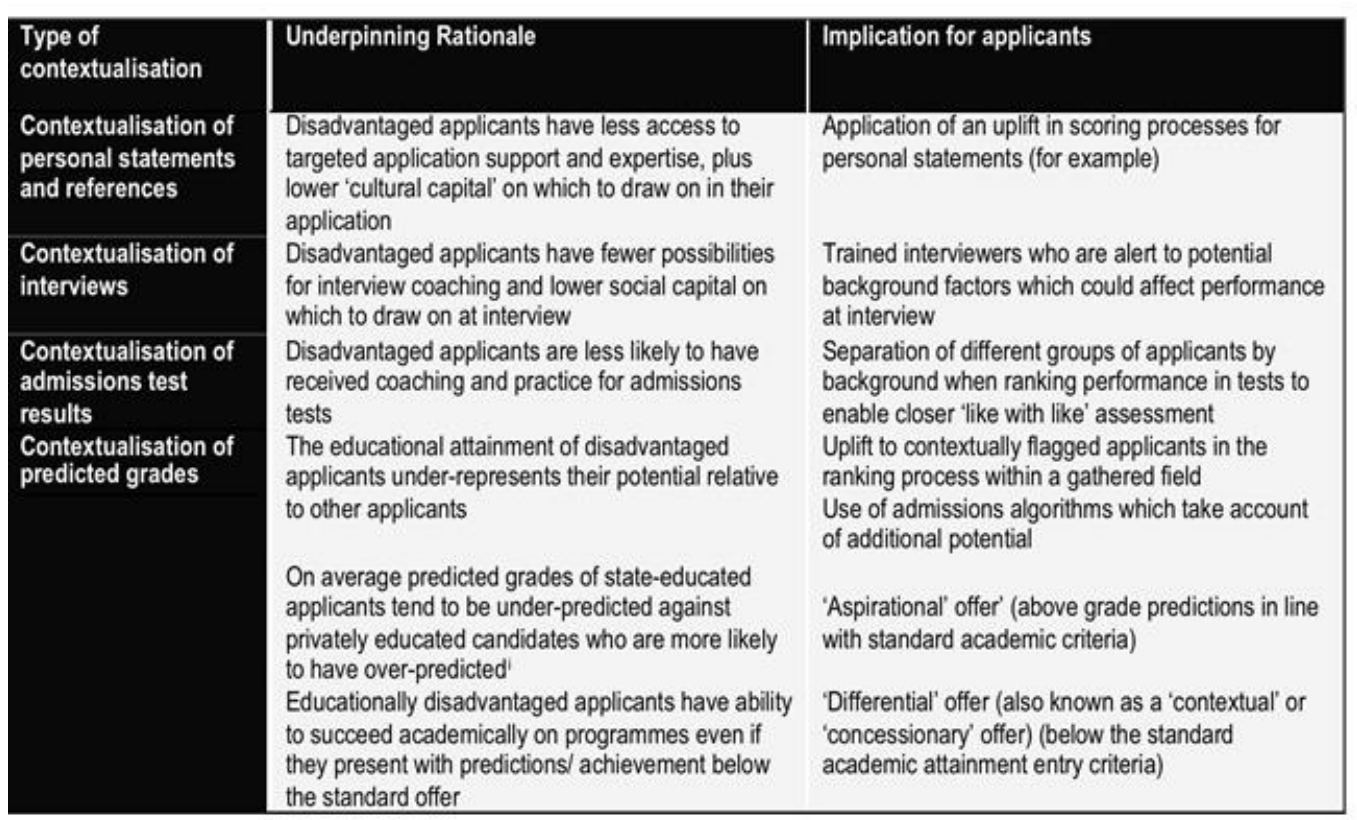

\section{Discussion}

HE access matters for social mobility and an array of other life outcomes. Identifying admissions practices such as contextual admissions that can mitigate for the socio-economic awarding gap in prior education is an important and necessary step for achieving more equality in HE participation overall.

Within our sample of nine highly selective HEls, the task of contextualising applicants during the undergraduate application process has led to embedded approaches emerging. This progresses fair access objectives. Our admissions decision-makers favoured highly individualised conceptions of merit. They used contextual data to aid such an individualised assessment, to inform interview and shortlisting decisions and for making differential or lower offers. Lowering offer grades was less common among our case study institutions, but it was considered very effective in diversifying the study body by those using it. We did not find any appetite among our case studies for extending holistic admissions considerations to include non-academic factors as is practised in e.g. the U.S.A.. Instead, we found a differentiation between those seeking to triangulate different measures to gain in-depth knowledge of each applicant, and those who favoured using metric-based cut-offs for contextualisation, with the latter approach being less precise but also less time-intensive.

We found institutional governance structures for contextual data use are important since contextual data in admissions require a high level of forward planning, extensive resource commitment, and collaboration between different parts of institutions. Among our case studies, effective use of contextual data clustered with contextualisation aligning with institutional targets; a culture of monitoring application decisions; building the evidence base through internal research; developing internal expertise; pro-active external communication; making contextual indicators accessible to applicants; and promoting awareness of contextual data in admissions amongst target groups. 
However, the use of contextual data as an equalising intervention in higher education access faces a range of ideological and practical barriers. Ideological concerns are around readiness for success, and competing agendas such as positions in league tables, based on selectivity at entry. Practical barriers to implementation include: data availability; resourcing; developing an evidence base; skills for working with the data; and - particularly in devolved admissions systems - the training of large numbers of decisionmakers. The present research also showed that duplication of effort at institutional level is currently large, without a central resource for all data needs.

For policymakers, our respondents requested better measures of disadvantage capable of being applied across the UK nations, since local difference in data is problematic for higher education providers that have applicants from each of these countries. The wished the Department for Education supported access to better individual-level student and school-level performance data. UCAS was identified as having potential for leadership on contextual data acquisition. Respondents were also mindful that the diversity of the English higher education sector makes a single approach to contextualisation unlikely, but that differential contextual admissions policies by providers make it challenging for applicants and those supporting them to understand the opportunities for admission at different institutions.

Respondents were in favour of some sector-wide movement on differential offers as a potentially great collective gain for both institutions and individual applicants.

For researchers, there are empirical and theoretical gaps that still need to be filled. Empirically, we need a firmer evidence base of the impact and potential support requirements of students admitted to university with dropped grades. While there is some evidence of equipotential among students from different backgrounds entering university with different grades (e.g. Ogg et al., 2009; Hoare \& Johnson, 2011; Taylor et al., 2013), what constitutes raw potential in HE has a weak evidence-base and requires re-evaluation in light of continuous changes in young people's qualifications. Moreover, our interviewees told us that institutional recruitment goals were a stronger driver for dropping grades than research evidence on the minimum required to succeed. Furthermore, much empirical work is required regarding how institutions currently use and can use data from contextual admissions to enhance and potentially target support for admitted students to help them succeed at and progress beyond university.

There is also a continued need to critically engage and theorise contextual admissions. One fruitful avenue could be using a Ricoeurian lens for understanding the dynamic between discourses of the teleology and the archaeology of the self in positioning the purpose of contextual admissions (Ricoeur, $1983,1984,1987)$. It remains important to be mindful that contextual admissions may, with the best intentions and with good outcomes for beneficiaries, serve to further cement and legitimise an unequal higher education system that privileges the status signal of higher education institutions over the curriculum knowledge (McLean, Abbas, \& Ashwin, 2017), and reproduces rather than breaks the wider structures of inequality.

The main argument crystallising from the present work highlights the importance of increasing transparency of contextual data policies to applicants, and the potential benefits of applying contextualisation at different points. This adds a new argument to previous research which has called for more institutions to adopt a progressive approach to contextual offers (Boliver et al., 2017; Sundorph, Vasilev, \& Coiffait, 2017). It would be a helpful step-change not only some but all institutions published their contextual offers, thus providing greater transparency to applicants in terms of their options. Indeed, we propose that radical transparency, a radical increase in the openness of how it works, should be applied to the use of contextual data in admissions, and admissions decisions generally; applicants, those advising them, and those making admissions decisions should all know exactly what they are looking for and be happy and able to explain this in a transparent way. A similar call for radical transparency has been made in the US during the time this piece has been in peer review (Morrison \& Kahlenberg 2019). Also, during the review process, further international work has occurred that is highlighting the global rise of contextualised or 'wholistic' admissions and the shared challenges institutions face (Bastedo, in press 2021).

Overall, contextual data can make a contribution to enhancing higher education access. Contextualising applicants in selective universities is an opportunity to offer relatively high-achieving disadvantaged 
young people an opportunity to access higher education institutions for which they would not otherwise be eligible. However, contextualised admissions is a stand-alone measure for neither issues of social mobility, nor the wider issues of inequality in society. The contextual data movement is ultimately individualising the response to broader structural inequalities in society, related to deep-seated inequalities in access to wealth, health, networks, advice, and earlier education. If anything, it may legitimise and reinforce the existing hierarchical English higher education system: it can make access a little bit broader but it does so within the constraints of the existing system, without necessarily provoking change. Perhaps it is the power of contextualisation to make small progress while not upsetting the existing system that makes it an attractive tool throughout political parties and institutions.

\section{References}

All Party Parliamentary Group on Social Mobility (2017). The class ceiling: Increasing access to the leading professions. London: APPG.

Anders, J. (2017). The influence of socio-economic status on changes in young people's expectations of applying to university. Oxford Review of Education, 43, 381-401.

Archer, L., DeWitt, J., \& Wong, B. (2014). Spheres of influence: What shapes young people's aspirations at age 12/13 and what are the implications for education policy? Journal of Education Policy, 29, 58-85.

Bastedo, M. N. (in press 2021). "Holistic Admissions as a Global Phenomenon." In Heather Eggins, Anna Smolentseva, and Hans de Wit (Eds.), The Next Decade: Challenges for Global Higher

Education. Leiden: Brill.

Bastedo, M, Bell, D., Howell, J.S., Hsu, J., Hurwitz, M., Perfetto, G., Welch, M. (forthcoming 2021) Identifying Contexts for Achievement: Field Experiments on Information Use in College Admissions, American Educational Research Journal

Boliver, V., Crawford, C., Powell, M., \& Craige, W. (2017). Admissions in context: The use of contextual information by leading universities. London: Sutton Trust.

Chowdry, H., Crawford, C., Dearden, L., Goodman, A., \& Vignoles, A. (2013) Widening participation in higher education: Analysis using linked administrative data. Journal of the Royal Statistical Society: Series A (Statistics in Society), 176, 431-457.

Crawford, C. (2014). The link between secondary school characteristics and university participation and outcomes. London: Institute for Fiscal Studies.

Gorard, S., Boliver, V., Siddiqui, N., Banerjee, P., \& Morris, R. (2017). Which are the most suitable contextual indicators for use in widening participation to HE? Working Paper. School of Education and School of Applied Social Sciences, Durham University, Durham.

Harrison, N., \& Waller, R. (2018). Challenging discourses of aspiration: The role of expectations and attainment in access to higher education. British Educational Research Journal, 44, 5, 914-938.

Hartocollis, A. (2019a, December 10). University of California is sued over use of SAT and ACT in admissions. New York Times.

Hartocollis, A (2019b, August 27). SAT 'Adversity Score' is abandoned in wake of criticism. New York Times.

Higher Education Funding Council for England (HEFCE) (2003). Schooling effects on higher education achievement. Bristol: HEFCE. (HEFCE 2003/32) 
HEFCE (2005) Schooling effects on higher education achievement - further analysis: entry at age 19. Bristol: HEFCE. (HEFCE 2005/09)

HEFCE (2014). Differences in degree outcomes: key findings. Bristol: HEFCE. (HEFCE 2014/03)

Higher Education Steering Group. (2004). Fair admissions to higher education: recommendations for good practice (The Schwartz Report). London: Department for Education and Skills.

Hoare, A., \& Johnston. R. (2011). Widening participation through admissions policy: A British case study of school and university performance. Studies in Higher Education 36 (1), 21-41.

Jones, S., Pampaka, M., Swain, D., \& Skyrme, J. (2017). Contextualising degree-level achievement: an exploration of interactions between gender, ethnicity, socio-economic status and school type at one large UK University. Research in Post-Compulsory Education 22, 4, 455-476.

Kahlenberg, R. (2010). Affirmative action for the rich: Legacy preferences in college admissions. New York: The Century Foundation Press.

Lucas, S. R. (2001). Effectively maintained inequality: education transitions, track mobility and social background effects. American Journal of Sociology 106, 1642-1690.

Matthews, D. (2019, January 17). French university admissions: the crème de la crème? Times Higher Education.

McLean, M., Abbas, A., \& Ashwin, P. (2017). Quality in undergraduate education: How powerful knowledge disrupts inequality. London: Bloomsbury Publishing.

Milburn, A. (2012). University challenge: How higher education can advance social mobility. A progress report by the Independent Reviewer on Social Mobility and Child Poverty.

Morrison, A., \& Kahlenberg, R. (2019). Admissions policies lack credibility. The cure: radical Transparency. The Chronicle of Higher Education, March 21, 2019.

Mountford-Zimdars, A., Moore, J. \& Graham, J. (2016) Is contextualised admission the answer to the access challenge?, Perspectives: Policy and Practice in Higher Education, 20:4, 143-150, DOI: 10.1080/13603108.2016.1203369

Mountford-Zimdars, A. (2017) 'Can Holistic and Contextualised Admission (HaCA) widen access at highly selective universities? Experiences from England and the United States' in A. MountfordZimdars and N. Harrison (eds.) Access to Higher Education: Theoretical perspectives and contemporary challenges. Abingdon: Routledge.

Mzangwa, S. (2019) The effects of higher education policy on transformation in post-apartheid South Africa. Cogent Education, 6, 1, 1592737. DOI: 10.1080/2331186X.2019.1592737

Office for Students (OfS). (2019, February 28). New 'What Works' centre to help universities cut equality gaps. OfS website. Retrieved from https://www.officeforstudents.org.uk/news-blog-andevents/press-and-media/new-what-works-centre-to-help-universities-cut-equality-gaps/

OfS. (2020, January 29). Our approach to access and participation. OfS website. Retrieved from https://www.officeforstudents.org.uk/advice-and-guidance/promoting-equal-opportunities/ourapproach-to-access-and-participation/

Ogg, T., Zimdars, A., \& Heath, A. (2009). Schooling effects on degree performance: a comparison of the predictive validity of aptitude testing and secondary school grades at Oxford University. British Educational Research Journal, 35, 5, 781- 807.

Pennington, B. (2019, May 9). Lessons from a scandal: Colleges quietly tighten the athletic recruiting process. New York Times. 
Raftery, A., \& Hout, M. (1993). Maximally maintained inequality: Expansion, reform, and opportunity in Irish education. Sociology of Education 66, 41-62.

Reay, D. (2017). Miseducation. Inequality, education and the working classes. Bristol: Policy Press.

Ricoeur, P. (1983-1987). Time and narrative (Temps et Récit) (Vols. 1-3). (K. McLaughlin and D. Pellauer, trans. (1984-1988)). Chicago: University of Chicago Press.

Shiner, M., \& Noden, P. (2014) 'Why are you applying there?': 'race', class and the construction of higher education 'choice' in the United Kingdom. British Journal of Sociology of Education, 36, 8, 11701191.

Stevens, M. (2007). Creating a class. Cambridge, MA: Harvard University Press.

Sundorph, E., Vasilev, D., \& Coiffait, L. (2017). Joining the elite: how top universities can enhance social mobility. London: Reform.

Supporting Professionalism in Admissions (SPA) (2015). Use of contextualised admissions survey report 2015 (with HEDIIP). Cheltenham: SPA.

Sutton Trust. (2011). Degrees of success. University chances by individual school. London: Sutton Trust.

Sutton Trust. (2017). Admissions in context: The use of contextual information by leading universities. London: Sutton Trust.

Taylor, T., Rees, G., Sloan, L., and Davies, R. (2013). Creating an inclusive higher education system? Progression and outcomes of students from low participation neighbourhoods at a Welsh university. Contemporary Wales, 26, 138.

UCAS (2017). 2017 End-of-cycle Report. Cheltenham: UCAS.

UCAS (2019). UCAS end of Cycle Report. Cheltenham: UCAS.

Zimdars, A. M. (2016). Meritocracy and the university: Selective admission in England and the United States. London: Bloomsbury. 